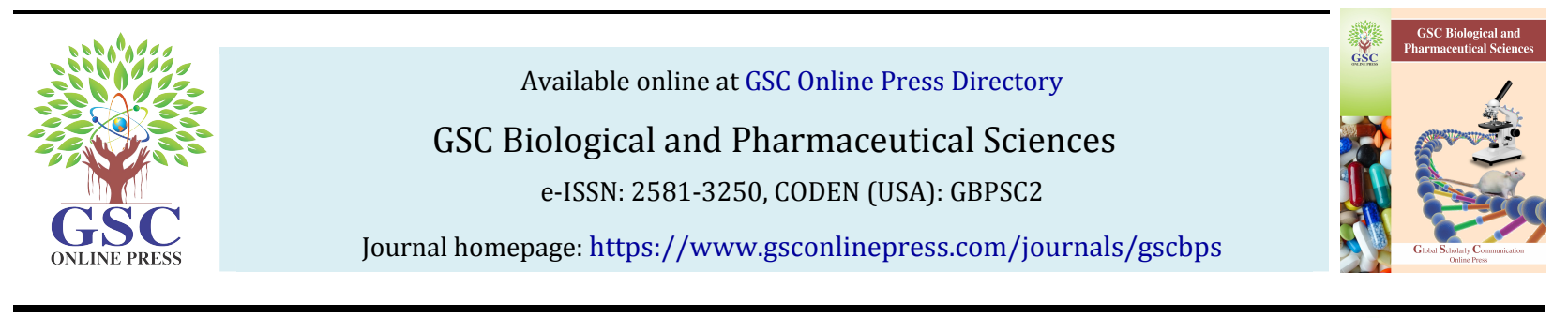

(RESEARCH ARTICLE)

\title{
The structure of soil macrofauna communities on islands of the Volga river
}

\author{
Vavilov Dmitriy Nikolaevich *, Sukhodolskaya Raisa Anatolyevna and Gordienko Tatyana Alexandrovna \\ Laboratory of Biomonitoring, Institute of Ecology and Mineral Resource Management Academy of Sciences of Tatarstan \\ Republic, Kazan, Tatarstan, Russia.
}

Publication history: Received on 06 March 2019; revised on 03 April 2019; accepted on 12 April 2019

Article DOI: https://doi.org/10.30574/gscbps.2019.7.1.0036

\begin{abstract}
River islands are of great interest in terms of habitat fragmentation and varying abiotic factors. This study presents results of observation of varied in size and condition islands of Kuybyshev reservoir, located in the middle flow of the Volga river. We recorded 27 taxonomic groups which related to 3 types, 7 classes and 12 invertebrate orders. Soil macrofauna abundance on islands was comparable with the mainland biotopes. The main factor influencing soil macrofauna structure was soil type. Island size and height, anthropogenic impact and vegetation contributed into soil community's structure variation too.
\end{abstract}

Keywords: River islands; Soil macrofauna; Kuybyshev reservoir; Abiotic factors

\section{Introduction}

Islands host a disproportionate fraction of global biodiversity, often characterized by distinctive faunas [1], and therefore represent a model system to better understand general patterns in biogeography. Insular populations are typically exposed to high risks of extinction as restricted habitats can easily become unsuitable because of stochastic events or human disturbances acting at both local (habitat fragmentation, alteration, invasion by alien species) and global scales [2]. Understanding the factors that drive the emergence, maintenance and loss of island biodiversity is crucial for planning and implementing evidence-based conservation prioritization and protection measures [3].

Prevailing majority of islands fauna studies concern the ocean islands $[4,5]$. We found the single publication on islands biota at the large lake islands. The authors investigated the effects of habitat properties and life history on the occurrence and community structure of 71 carabid beetle species inhabiting 15 lake islands in north-east Poland. Island properties, particularly area and habitat quality, were positively linked to the occurrences of $42 \%$ of the species and correlated with species richness and $\beta$-diversity. Life history traits (hibernation type, dispersal ability and average abundances) significantly influenced species occurrences. Thus, site and species properties influenced the spatial distribution of species and macroecological patterns on islands [6]. These results do not point to habitat heterogeneity or isolation as significant factors that influence island colonization of ground beetles. Therefore, the most parsimonious explanation for the spatial occurrences of Carabidae on lake islands remains a neutral model where colonization is a random process at the individual level irrespective of species identity [7].

MacArthur and Wilson's island biogeography theory $(1963,1967)$ examines the influence of geographical factors, such as area and distance from the mainland, on the total number of species present on an island or habitat[8]. However, there is still considerable debate on which mechanism is most appropriate in explaining species-area relationships. For example, many case studies on Baltic Sea islands showed that, although habitat diversity might be important, a significant increase in species number with area per se exists [9]. Area was the only factor influencing species richness

\footnotetext{
${ }^{*}$ Corresponding author

E-mail address: sabantsev.ipen@gmail.com
} 
of carrion beetles on islands. Moreover, distance from the mainland and close islands did not significantly influence to carrion beetles. In addition, geographic location in the same Sea did not influence beetles assemblages. Taken together, the results of this study indicated that carrion beetles on Korean islands were largely affected by island size and that dispersal was stochastic [10].

Another topic about islands biota is habitat heterogeneity. Some authors concluded that habitat diversity had little predictive power in explaining species richness. Islands close to each other (a few hundred metres apart) accumulated species at a slower rate than did scattered islands, as island size increased [11].

On the other hand the opinion exists that habitat loss and fragmentation are considered as the leading drivers of biodiversity loss. The small-island effect (SIE) can be used to predict species extinctions resulting from habitat loss and has important implications for species conservation. However, to date, no study has explicitly evaluated the prevalence of SIEs in habitat islands. The authors compiled 90 global datasets to systematically investigate the prevalence and underlying factors determining the ubiquity of SIEs in habitat island systems. Among the 90 datasets, SIEs were unambiguously detected in 36 cases. They found significant effects of habitat island types and taxon groups on the threshold area of SIEs. The number of islands, area range, species range, island type and taxon group were key variables that determined the prevalence of SIEs [12]

The object of the study was the soil macrofauna. The macrofauna includes soil invertebrates from $2 \mathrm{~mm}$ and more in size - earthworms, arachnids, centipedes, insects (adults and larvae) etc. Soil marcofauna presents an essential part of soil-dwelling invertebrates community. Their feeding and burrowing activity structures soil in the best manner to provide enhancing of circle of nutrients. Some groups of soil macrofauna play the key role in destruction processes in soil.

The aim of this study was to evaluate key factors which affect biodiversity of soil macrofauna on the river islands.

\section{Material and methods}

\subsection{Collection sites and insect sampling}

The study area is the islands of the Kuibyshev reservoir, located in the middle flow of the Volga River of the Russian Federation. The Kuybyshev reservoir was built in 1957. It's the largest not only among the reservoirs of the VolgaKama cascade, but also among the reservoirs of Europe [13]. Many islands appeared after its organization. It is located in the central part of the Middle Volga region. Most of its area is located within the Republic of Tatarstan (50.7\%). The reservoir is extended in the meridional direction across the Russian Plain from 53 to 56 degrees north latitude. The total length of the reservoir is more than $600 \mathrm{~km}$ with a width of up to $40 \mathrm{~km}$ in the area of the confluence of the Volga and Kama rivers.

Kuibyshev reservoir is the one of valley type. A large area of its bed includes floodplain and flooded terraces of the Volga and Kama valleys.The reservoir is located in the zone of temperate continental climate. It begins in the forest zone, crosses the entire forest-steppe, its southern extremity adjoins the steppe landscape zone [13].The Kuibyshev reservoir is a series of lake-like extensions (reaches), interconnected by constrictions within the old bed. The Kazan (Volga) area of variable accumulation pressure (KAVAP) [13], where our studies were conducted, is distinguished from the reach.

The studied archipelago is located from the city of Zelenodolsk downstream to the mouth of the river Meshe near the village of Teteyevo $\left(55^{\circ} 49^{\prime} 33.44^{\prime \prime} \mathrm{N}, 48^{\circ} 31^{\prime} 55.99^{\prime \prime}\right.$ E to $55^{\circ} 25^{\prime} 08.00^{\prime \prime} \mathrm{N}, 4^{\circ} 08^{\prime} 43.46^{\prime \prime}$ E). Totally 29 islands of the Kuibyshev reservoir and 31 habitats were investigated. When choosing the islands we took into account the following: flooded island or not, sufficient area for taking 8 samples (at least 5 meters from each other), samples were taken in one of the most represented island phytocenosis, uniformly throughout the archipelago.

Studies of soil macrofauna were carried out in the summer period from July to August 2018. Animals were collected by the standard soil-zoological method [14] - manual analysis of soil samples of $25 \times 25 \mathrm{~cm}$ in size and $15-20 \mathrm{~cm}$ in depth (8 samples on the island), the abundance of pedobionts was measured in individuals per $\mathrm{m}^{2}$. Totally 248 samples were taken and 1962 individuals of soil invertebrates were found.

\subsection{Material processing}

For statistical analysis, the data was classified into 3-5 categories depending on the factor. 
The size of the islands varied in the range of $0.52-257.54 \mathrm{~m}^{2}$, this value was divided into three categories: the first included islands with an area of up to $86 \mathrm{~m}^{2}$ (23 islands), the second - more than $86 \mathrm{~m}^{2}$ and less than $172 \mathrm{~m}^{2}(5$ islands), the third is more than $172 \mathrm{~m}^{2}$ (3 islands).

The anthropogenic impact was classified according to the degree of recreational load on the island: stage 1 - weak, at which the island is scarcely visited (8 islands), stage 2 - medium, where the island is actively visited by fishermen (fireplaces, tables, benches) (15 islands), and stage 3 - an island with a strong anthropogenic load (recreation, fishing, cottages) (8 islands).

The type of soil was determined by soil scientists. Ph.D. V.I. Kulagina and Ph.D. A.B. Alexandrova, employees of the Institute of Problems of Ecology and Subsoil use of the Academy of Sciences of the Republic of Tatarstan. Five types of soil were identified: 1 - alluvial (21 islands), 2 - bulk sand (2 islands), 3 - sod-podzolic (4 islands), 4 - forest grey ( 3 islands), and 5 - urbanozem (1 island). Due to the fact that urbanozem is represented only on one island, it wasn't included in multidimensional analysis.

The biotope type was named for the prevalence of woody vegetation at the sampling site: 1 - willow (12 islands), 2 meadow (9 islands), 3 - pine-tree ( 3 islands), 4 - poplar ( 5 islands), 5 - oak forest ( 2 islands).

The height of the islands according to Shuttle Radar Topography Mission by NASA [https://lpdaac.usgs.gov/news/nasa-shuttle-radar-topography-mission-srtm-version-30-global-1-arc-second-datareleased-over-europe-north-america-and-south-america, last accessed on 16/04/2019] varied from 45-69.79 m, and it was divided into three categories: 1 - island height up to $53.26 \mathrm{~m}$ (18 islands), 2 - from $53.27 \mathrm{~m}$ to $61.53 \mathrm{~m}$ (11 islands), from $61.54 \mathrm{~m}$ to $69.79 \mathrm{~m}$ (2 islands).

\subsection{Statistical analysis}

Mathematical data processing performed by the method of descriptive statistics and multidimensional discriminant analysis in PP Statistica [15].

The goal of the multidimensional analysis was to investigate the differences of islands by factors, based on the taxonomic structure and population of the soil invertebrate macrofauna community. The Lambda Wilks Index is a statistics used to estimate the power of discrimination. Its value varies from 1.0 (there is no discrimination) to 0.0 (complete discrimination) [16]. Squared Mahalanobis distance is a measure of the distance between vectors of random variables, which generalizes the concept of the Euclidean distance or the distance of each observation from the centroid of a group [17].

\section{Results}

The macrofauna of the islands consisted of 27 taxonomic groups which related to 3 types, 7 classes and 12 invertebrate orders. They were Earthworms (Lumbricidae), Molluscs (Mollusca), Woodlice (Oniscoidea), Spiders (Aranea), Harvestmen (Opiliones), Diplopods (Diplopoda), Centipedes (Geophilidae, Lithobiidae), Cockroaches (Blattodea), Earwigs (Dermaptera), Cicads (Cicadidae), True bugs (Hemiptera), Net-winged insects (Neuroptera), Ground beetles (Carabidae), Diving beetles (Dytiscidae), Hister beetles (Histeridae), Carrion beetles (Silphidae), Rove beetles (Staphylinidae), Darkling beetles (Tenebrionidae), Earth-boring scarab beetles (Geotrupinae), Scarabs (Scarabaeidae), Soldier beetles (Cantharidae), Click beetles (Elateridae), Round fungus beetles (Leiodidae), Ladybugs (Coccinellidae), Leaf beetles (Chrysomelidae), Weevils (Curculionidae), Caterpillars (Lepidoptera), Wasps (Hymenoptera), Flies (Diptera).

Lumbricidae (average 49.3\%), Insecta (25.7\%), Lithibiidae (11.4\%), Arachnida (7.6\%) dominated in the soil. Among insects Carabidae (6.4\%) and Elateridae (6.1\%) were numerous. The abundance of soil macrofauna varied from 10 to 374 individuals $/ \mathrm{m}^{2}$ (on average 126.6 individuals $/ \mathrm{m}^{2}$ ). The low number of invertebrates was noted in soils under young willow on sandy alluvial soil, and high - in soil under mature willow on humid-rich alluvial soils.

The average abundance of pedobionts on islands of different size varied (Fig. 1). The largest number of macrofauna was on large islands, the smallest was on medium ones, and i.e. area did not affect greatly macrofauna number.

The average number of soil invertebrates appeared to become lower with increasing anthropogenic load (Fig. 2). However, macrofauna abundance at the islands with medium and heavy loads were not significantly different. 


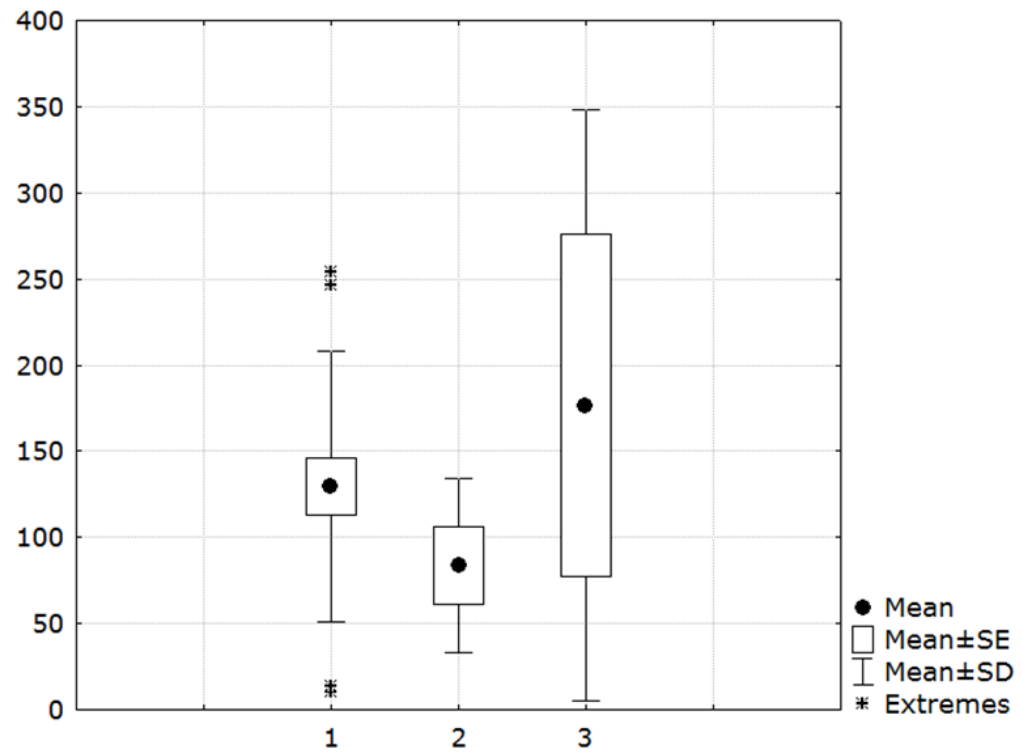

Figure 1 Pedobionts abundance (individuals $\left./ \mathrm{m}^{2}\right)$ in relation to the size of islands (1 - small islands, 2 - medium islands, 3 - large islands).

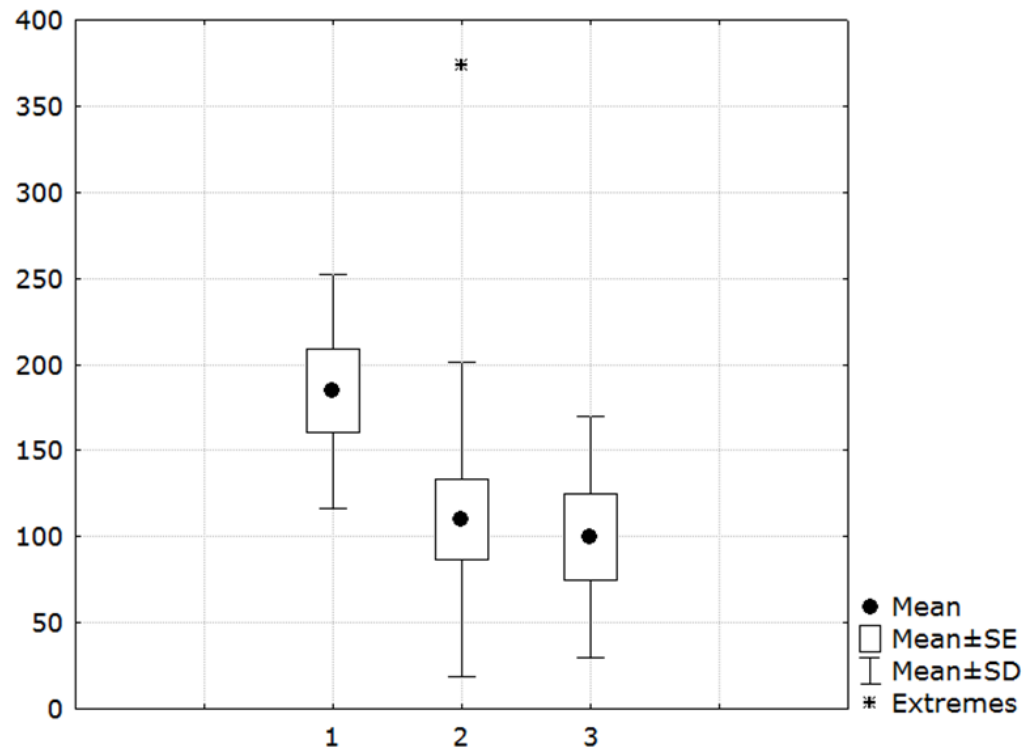

Figure 2 Pedobionts abundance (individuals $/ \mathrm{m}^{2}$ ) and their errors in relation to the degree of anthropogenic impact on the islands (1 - low level, 2 - medium level, 3 - high level)

The average abundance of soil invertebrates according to soil type was not significantly different between islands (Fig. 3). 


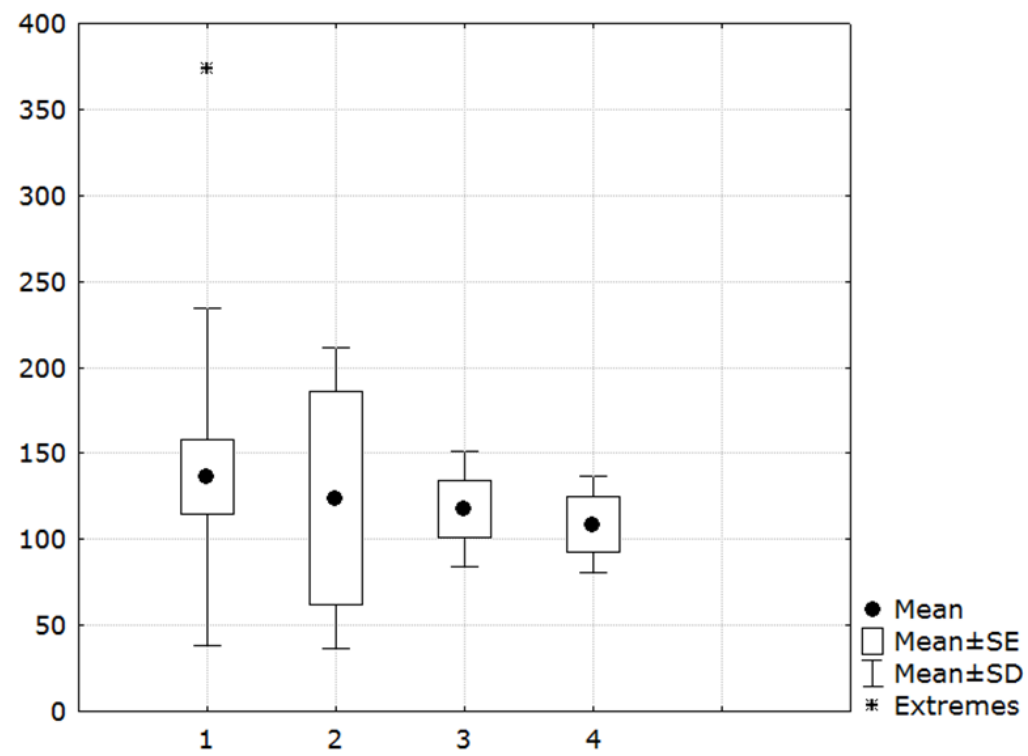

Figure 3 Pedobionts abundance (individuals $/ \mathrm{m}^{2}$ ) and their errors in relation to soil type (1 - alluvial, 2 - bulk sand, 3 - sod-podzolic, 4 - forest grey)

The highest abundance of pedobionts was found on islands with willow thickets (average number of 168.3 individuals $/ \mathrm{m}^{2}$ ) (Fig. 4), the smallest was in pine forests (66.7 individuals $/ \mathrm{m}^{2}$ ). The other habitats were approximately the same (95-116.8 individuals $\left./ \mathrm{m}^{2}\right)$.

The height of the islands did not affect the total number of pedobionts (Fig. 5).Thus, the only type of biotope and the degree of anthropogenic impact affected significantly the average abundance of macrofauna on islands.

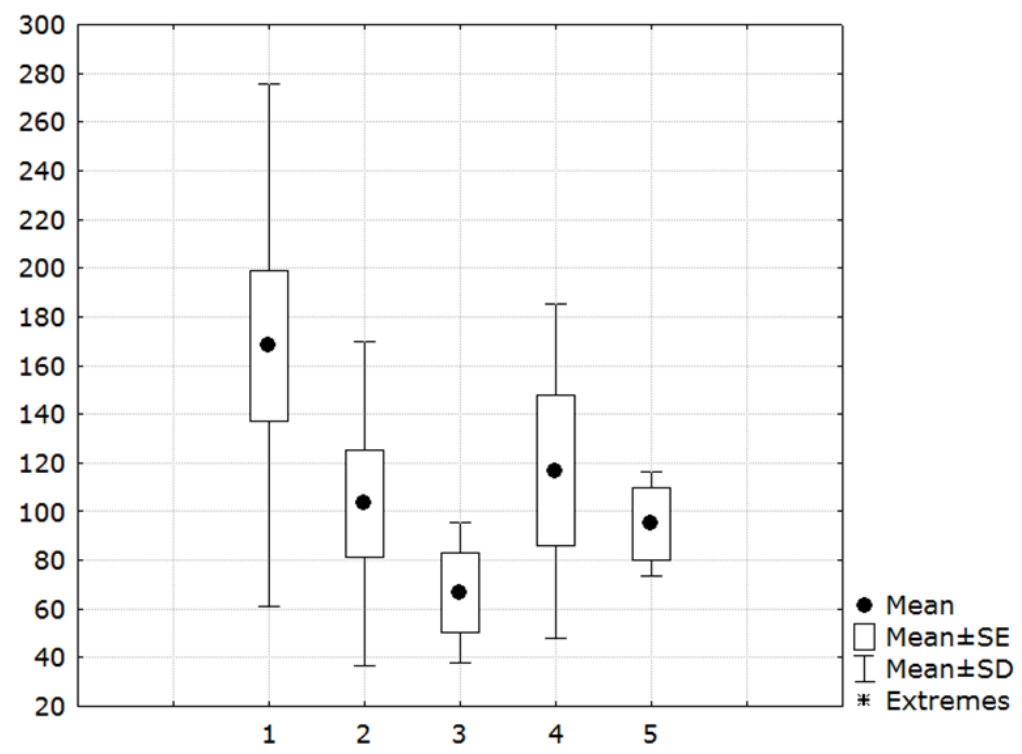

Figure 4 Pedobionts abundance (individuals $\left./ \mathrm{m}^{2}\right)$ and their errors in relation to the type of biotope (1 - willow, 2 meadow, 3 - pine-tree, 4 - poplar, 5 - oak forest) 


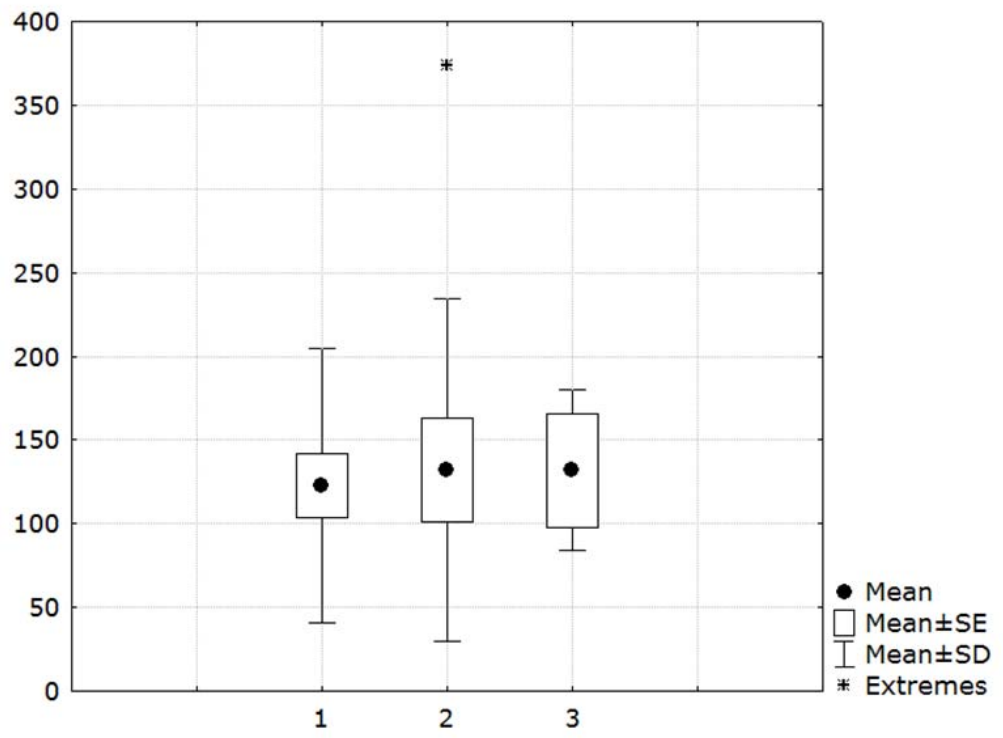

Figure 5 Pedobionts abundance (individuals $\left./ \mathrm{m}^{2}\right)$ and their errors in relation to island height $(1-$ low, 2 - medium, 3 - the highest)

The multidimensional analysis of the obtained results showed that all factors influenced the structure and population of the soil macrofauna (Table 1). However, their significance for the soil population was different and could be built into a sequence in which Wilks lambda increased and the Mahalanobis distance decreased. Thus, in our opinion, the type of soil had the greatest impact, than the height of the island, its area, anthropogenic impact and, to a lesser extent, the type of biotope.

Table 1 Results of discriminant analyses, when different factors were taken as predictors

\begin{tabular}{|c|c|c|c|c|}
\hline \multirow[t]{2}{*}{ Factor } & \multirow{2}{*}{$\begin{array}{l}\text { Lambda } \\
\text { Wilks }\end{array}$} & \multicolumn{2}{|l|}{$\begin{array}{l}\text { Squared } \\
\text { distance }\end{array}$} & \multirow{2}{*}{$\begin{array}{l}\text { Groups, } \\
\text { the major loading fell on }\end{array}$} \\
\hline & & Min & $\operatorname{Max}$ & \\
\hline Soil type & $\begin{array}{l}0.00024 \\
p<0.0000\end{array}$ & $117.2^{*}$ & 1203.8 & $\begin{array}{l}\begin{array}{l}\text { Diplopoda, } \\
\text { Histeridae, }\end{array} \text { Carabidae, } \\
\text { Staphylinidae, } \\
\text { Chrysomelidae, Opiliones, Scarabaeidae } \\
\text { and Insecta }\end{array}$ \\
\hline Height & $\begin{array}{l}0.00795 \\
p<0.0000\end{array}$ & 9.1 & 798.0 & $\begin{array}{l}\text { Diplopoda, Blattodea, Histeridae, } \\
\text { Staphylinidae, Lithobiidae, Oniscoidea }\end{array}$ \\
\hline $\begin{array}{l}\text { The area of the } \\
\text { island }\end{array}$ & $\begin{array}{l}0.01564 \\
p<0.0000\end{array}$ & 24.7 & 467.9 & $\begin{array}{l}\text { Tenebrionidae, Lumbricidae, Blattodea, } \\
\text { Carabidae, Cantharidae, Dytiscidae, } \\
\text { Cicadidae, Hymenoptera, Mollusca, } \\
\text { Scarabaeidae }\end{array}$ \\
\hline Human impact & $\begin{array}{l}0.01222 \\
p<0.0090\end{array}$ & 18.4 & 108.1 & $\begin{array}{l}\text { Tenebrionidae, Insecta, Histeridae, } \\
\text { Leiodidae, Dytiscidae, Cantharidae }\end{array}$ \\
\hline Biotope type & $\begin{array}{l}0.04232 \\
\mathrm{p}<0.0001\end{array}$ & 6.2 & 34.5 & $\begin{array}{l}\text { Dermaptera, Blattodea, Lithobiidae, } \\
\text { Oniscoidea, Lepidoptera }\end{array}$ \\
\hline
\end{tabular}

The type of soil was the main factor that affected macrofauna assemblages' structure. So we carried out discriminant analysis using "type of soil" as predictor (Fig. 6, Table 2). 
The major loading fell on diplopods, earwigs, cockroaches, Hister beetles, ground beetles, flies, rove beetles, woodlice, leaf beetles, harvestmen, Scarabs, and other insects.

Table 2 Squared Mahalanobis distance when assessing the impact of soil type on the structure and population of island pedobionts communities

\begin{tabular}{llll}
\hline Soil type & Alluvial & Bulk sand & Sod-podzolic \\
\hline Alluvial & 0 & & \\
Bulk sand & $631.5^{*}$ & 0 & 0 \\
Sod-podzolic & $384.7^{*}$ & $241.5^{* *}$ & $723.8^{*}$ \\
Forest grey & $117.2^{* *}$ & $1203.8^{*}$ &
\end{tabular}

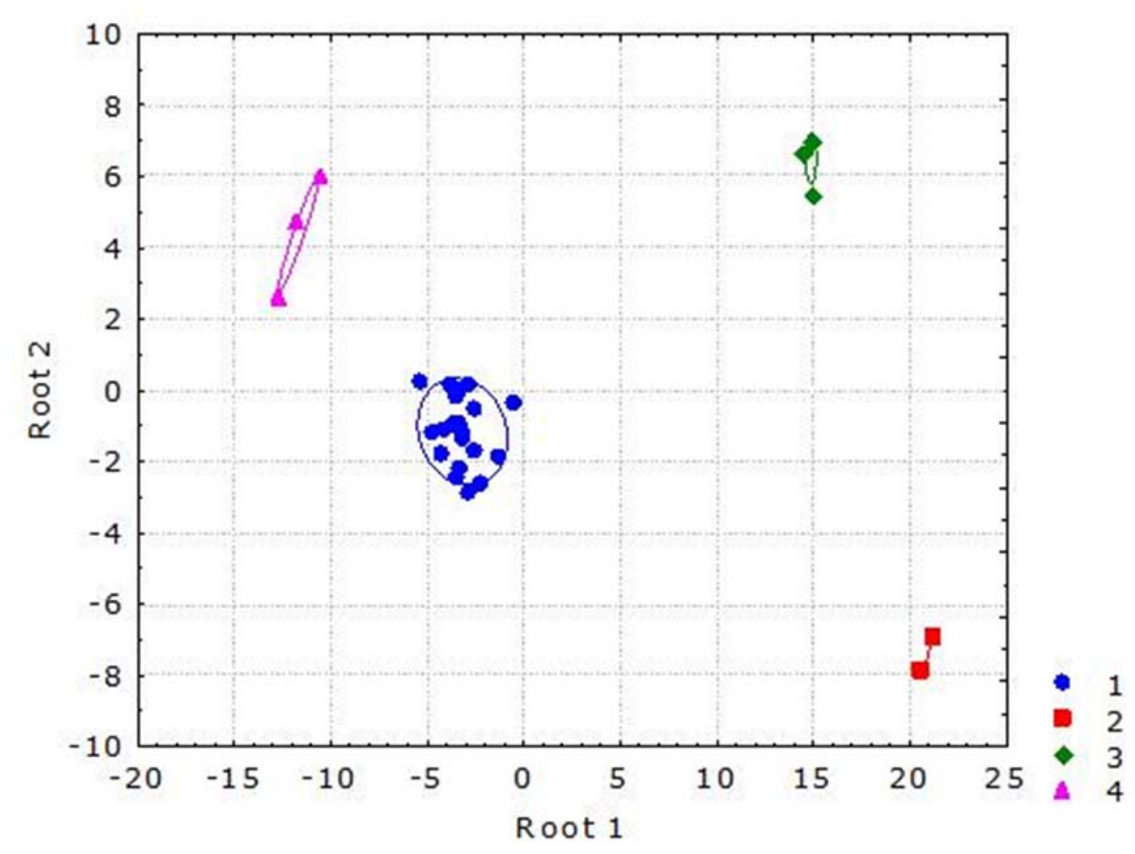

Figure 6 Biplot of discriminant analysis results (1 - alluvial, 2 - bulk sand, 3 - sod-podzolic, 4 - forest gray)

Thus, multidimensional analysis revealed statistically significant differences in the soil macrofauna communities structure relatively to the soil type.

\section{Discussion}

The number of macrofauna of the studied islands was comparable and sometimes exceeded the corresponding values for deciduous forests, pine forests and meadows of the Volga-Kama Reserve and natural biotopes of the Republic of Tatarstan $[18,19]$. The number of pedobionts estimated during the island expeditions of the 90th, was the highest on the islands of the second group (176 ind./sq.m) [20]. That group located on the line from 55 $51^{\prime} 15^{\prime \prime} \mathrm{N}, 48^{\circ} 16^{\prime} 19^{\prime \prime} \mathrm{E}$ to $55^{\circ} 46^{\prime} 19^{\prime \prime} \mathrm{N}, 49^{\circ} 00^{\prime} 47^{\prime \prime}$ E. In our studies the number of soil invertebrates on some islands reached $250-370$ ind./sq.m. The same conclusion can be drawn with regard to specifically some groups of invertebrates - ground beetles, click-beetles.

According to some authors [21], temperature, isolation and human activity have a significant impact on the biodiversity of insects and vascular plants on the islands. They point to the relationship between the diversity of vascular plants and insects. In our study all investigated factors (area, anthropogenic impact, height and vegetation) affected macrofauna diversity on the islands. But the major effect was drawn from soil type. It was expected, because macrofauna usually inhabits upper layers of the soil. For sure, macrofauna community's structure preserved those 
characters that had been inherent to it before the reservoir was created. Literature on soil macrofauna on the islands macrofauna is very scarce, and we failed to find a single research in island soil invertebrates. Actually our study is the first, where it is estimated and reported. We did not study the turnover on the islands as it has been done by other authors [22, 23]. Moreover, conservation biologists and applied ecologists should consider the prevalence of small island effects (SIEs) when making management strategies in fragmented landscapes [12]. In our study we tried to contribute The Global Island Monitoring Scheme (GIMS) for monitoring the remaining native islands, using selected groups of arthropods as model taxa, that has been proposed by a collective of authors [24].

\section{Conclusion}

Totally 27 groups of soil macrofauna was collected on the islands. The abundance of invertebrates highly varied. Number and diversity of invertebrate soil communities on the river islands is comparable with the mainland biotopes. Soil macrofauna structure is affected mainly by soil type, though island size and height, anthropogenic impact and vegetation contribute into soil communities structure variation. Further investigations needed to clarify biota structure variation in river islands.

\section{Compliance with ethical standards}

\section{Acknowledgments}

We express our sincere gratitude to the colleagues of the Institute in the description of the islands studied.

\section{Disclosure of conflict of interest}

The authors declare that they have no competing interests.

\section{References}

[1] Whittaker RJ and Fernández-Palacios JM. (2007). Island biogeography: ecology, evolution, and conservation. Oxford University Press, New York, 251-252.

[2] Fordham DA and Brook BW. (2010). Why tropical island endemics are acutely susceptible to global change. Biodiversity and Conservation, 19(2), 329-342.

[3] Ladle R and Whittaker RJ. (2011). Conservation biogeography. John Wiley and Sons, Oxford, 201-212.

[4] Dapporto L, Cini A, Menchetti M, Vodă R, Bonelli S, Casacci LP, Dincă V, Scalercio S, Hinojosa JC, Biermann H and Forbicioni L. (2017). Rise and fall of island butterfly diversity: Understanding genetic differentiation and extinction in a highly diverse archipelago. Diversity and Distributions, 23(10), 1169-1181.

[5] Saito T, Hirano T, Prozorova L, Sulikowska-Drozd A, Sitnikova T, Surenkhorloo P, Yamazaki D, Morii Y, Kameda Y, Fukuda H and Chiba S. (2018). Phylogeography of freshwater planorbid snails reveals diversification patterns in Eurasian continental islands. BMC evolutionary biology, 2018, 18(1), 164.

[6] Zalewski M, Sienkiewicz P, Kujawa K, Hajdamowicz I and Ulrich W. (2012). Ground beetles on islands: on the effects of habitat and dispersal. Annales Zoologici Fennici, 49, 139-151.

[7] Ulrich W and Zalewski M. (2007). Are ground beetles neutral? Basic and Applied ecology, 8, 411-420.

[8] MacArthur RH and Wilson E0. (1967). The theory of island biogeography. Princeton University Press, Princeton, 68-70.

[9] As S. (1984). To fly or not to fly? Colonization of Baltic islands by winged and wingless carabid beetles. Journal of Biogeography, 11, 413-426.

[10] Choi SW, Cho YB and Kim DS. (2018). Area effect of distribution of Silphids (Coleoptera, Silphidae) on Korean islands. Journal of Asia-Pacific Entomology, 21, 695-700.

[11] Kotze DJ, Niemelä, J and Nieminen M. (2000). Colonization success of carabid beetles on Baltic islands. Journal of Biogeography, 27(4), 807-819.

[12] Wang Y, Chen C and Millien V. (2018). A global synthesis of the small-island effect in habitat islands. Proceedings of the Royal Society, 285, 1-8. 
[13] Kulagina VI, Alexandrova AB and Ivanov DV. (2018). Soils on islands of Kuibyshev reservoir. Kazan, 150.

[14] Gilyarov MS. (1975). Quantitation of big invertebrates (mesofauna). Methods of Soil Zoology, Nauka, Moscow, 12-29.

[15] Borovikov V. (2003). Statistica. Art of computer data analysis: for professionals. Piter, Saint Petersburg, 67-80.

[16] Meshalkina YL and Samsonova VP. (2008) Mathematical statistics in soil science: Practice. Max-Press, Moscow, 83-84.

[17] Khalafyan AA. (2008). STATISTICA: Statistic analysis of data. 3d edition. Student book. "Binom press", Moscow, 102-105.

[18] Aleinikova MM, Porfiryev VS and Utrobina NM. (1979). Parcel structure of spruce-broad-leaved forests in the east of the European part of the USSR. Nauka, Moscow, 23-24.

[19] Zherebtsov AK, Artemyeva IT, Sabirov RM and Shulaev NV. (2014). Cadastre of communities of soil dwelling invertebrates (macrofauna) in natural ecosystems of the Republic of Tatarstan. Kazan University, Kazan, 50-75.

[20] Boyko VA, Grigoryan BR, Ivanov DV and Ivliev VG. (2002). Island ecosystems of Kuybyshevreservoir. Kazan (Volga) area of variable accumulation pressure. "Fen" Press, Kazan, 150-169.

[21] Leihy RI, Duffy GA and Chown SL. (2018). Species richness and turnover among indigenous and introduced plants and insects of the Southern Ocean Islands. Ecosphere, 9(7), 1-15.

[22] Zalewski M and Ulrich W. (2009). Island Colonization of Carabidae: Neutrality or Habitat Choice? Israel Journal of Ecology and Evolution, 55(3), 253-262.

[23] Bell AJ. (2015). The Biogeography of Ground Beetles (Coleoptera: Carabidae) on the Islands of Lac la Ronge, Saskatchewan, Canada. Master of Science thesis, University of Alberta, Canada, 58-59.

[24] Borges PA, Cardoso P, Kreft H, Whittaker RJ, Fattorini S, Emerson BC, Gil A, Gillespie RG, Matthews TJ, Santos $\mathrm{AM}$ and Steinbauer MJ. (2018). Global Island Monitoring Scheme (GIMS): a proposal for the long-term coordinated survey and monitoring of native island forest biota. Biodiversity and conservation, 27(10), 25672586.

\section{How to cite this article}

Vavilov DN, Sukhodolskaya RA and Gordienko TA. (2019). The structure of soil macrofauna communities on islands of the Volga river. GSC Biological and Pharmaceutical Sciences, 7(1), 28-36. 